\title{
KRISIS MASKULINITAS DALAM PEMBENTUKAN IDENTITAS GENDER PADA AKTIVITAS KOMUNIKASI
}

\author{
Annisa Anindya \\ ${ }^{1)}$ Program Studi Ilmu Komunikasi, Universitas Dharma Andalas; annisa@unidha.ac.id
}

\begin{abstract}
ABSTRAK
Kategorisasi peran antara wanita dan pria di dalam lingkungan masyarakat membentuk stereotip gender. Stereotip gender ini menuntut pria dan wanita patuh akan kategorisasi tersebut, yakni maskulin dan feminin. Peran yang dibentuk masyakarat tersebut membentuk krisis akan mas kulinitas pada lelaki. Maskulinitas laki-laki dipertanyakan ketika mereka memiliki karakter yang bukan maskulin. Penelitian ini menggunakan metode penelitian kualitatif. Metode pengumpulan data untuk mendapatkan informasi adalah terlibat atau terjun langsung, mengadakan observasi, wawancara terbuka dan analisis dokumentasi. Iinforman pada penelitian ini didapatkan melalui teknik snowball sampling. Kemudian teknik analisis data yang digunakan adalah data collection, data reduction, data display, dan conclusion: drawing/verifying. Penelitian menghasilkan analisis mengenai pemahaman kritis bahwa identitas yang dihasilkan muncul karena adanya pemahaman androgini secara psikologis merupakan bentuk kecerdasan emosi. Laki-laki, mengalami krisis identitas terkait posisinya secara personal dan komunal di dalam mas yarakat dan karakter androgini menjadi pilihan dalam menunjukkan identitasnya.
\end{abstract}

Keywords: Peran gender, stereotip gender, feminin, maskulin, komunikasi

\begin{abstract}
The categorization roles between men and women forms gender stereotypes such as feminine and masculine. The role of the community formed a crisis of masculinity on men for having masculine traits. This research are using qualitative research method. Observation, open-interview, and document analysis methods are used in the data collecting proccess. The subject of this research is a male who observes and understands the general consencuss of gender stereotype in the society, and also have been through identity crisis regarding about gender terms. This research is using snowball sampling techniques with data analysis on data collection, data reduction, data display, dan conclusion: drawing/verifying .This reseacrh shows the critical understanding about acceptance on behalffor being a human. Catego rization among male and female for being feminine or masculine is barriers on communication. Thoses men produces the understanding to be androgynous person. And an identity as androgynous is needed as emotional intelligence in term of making effective communication.
\end{abstract}

Keywords: gender roles, gender stereotype, feminine, masculine, communication 


\section{PENDAHULUAN}

"Men are from Mars, Women are from Venus" sebuah buku yang ditulis oleh Gray (dalam Littlejohn \& Foss, 2009) yang menjelaskan bahwa wanita dan pria adalah berasal dari dua planet yang berbeda sehingga tercipta tembok perbedaan di antara keduanya. Lebih lanjut, Tannen (dalam Griffin, 2006) menjelaskan bahwa interaksi di dalam komunikasi antara wanita dan pria merupakan komunikasi cross-cultural, yang mana seperti cara menanggapi respon dan mengungkapkan keinginan serta harapan juga berbeda yakni wanita lebih kooperatif, mendukung dan setuju dalam memberikan saran sedangkan pria lebih argumentatif akan pendapat dan pandangannya bahkan bisa juga menentang serta mengeluarkan perintah.

Sedari awal, masyarakat sudah memberikan pemisah antara wanita dan pria. Masyarakat sudah membentuk kotak serta batasan-batasan akan peran wanita dan pria. Seorang lakilaki harus bersikap layaknya seorang pria, begitu juga dengan perempuan yang harus mengikuti standar kewanitaannya. Standar pria dan wanitia diciptakan sedemikian rupa, yakni berupa feminitas dan maskulinitas. Femininitas dan maskulinitas ini berkaitan dengan stereotip peran gender. Stereotip peran gender ini dihasilkan dari pengkategorisasian antara perempuan dan laki-laki, yang merupakan suatu representasi sosial yang ada dalam struktur pengetahuan (Myers, 1996). Tanpa disadari pemikiran bahwa laki-laki harus berani dan tidak boleh cengeng didaulat sebagai karakteristik yang harus dimiliki pria yang kuat, agar tidak dicap lemah. Sebaliknya, kelemahan diasosiasikan sebagai karakteristik perempuan. Sehingga apabila salah satu karakter melekat pada konsep yang lain dianggap menyimpang. Masyarakat membentuk keyakinan bahwa wanita dan pria memiliki peran gender (Mead dalam Oskamp \& Schultz, 2005), yakni meliputi harapan mengenai perilaku tertentu di dalam masyarakat.

\section{Konsep Diri dan Identitas}

Menurut Devito (2008), 'your self concept is your image of who you are'. Konsep diri ini mengungkapkan bagaimana kita memahami diri kita sendiri seperti apa yang kita rasakan, juga kekuatan dan kelemahan kita, berikut kemampuan dan keterbatasan yang hanya diri kita sendiri yang mengetahuinya. Epstein (1973) menyebutkan bahwa selfconcept memaparkan segala sesuatu tentang "the good me" dan "the bad me" untuk mengetahui lebih dalam siapa diri kita. Mead (dalam Griffin, 2012) mengklaim bahwa terbentuknya konsep diri adalah karena interaksi yang dilakukan bersama orang lain. Persepsi terhadap diri dapat diubah dan dibentuk karena konsep diri yang diyakini terus berkembang. Maka identitas juga didapatkan melalui interaksi. Konsep diri yang bersifat dinamis ini dapat bergerak menyesuaikan dengan situasi dan perubahan yang ada.

Gambar 1

The Sources of Self-Concept 


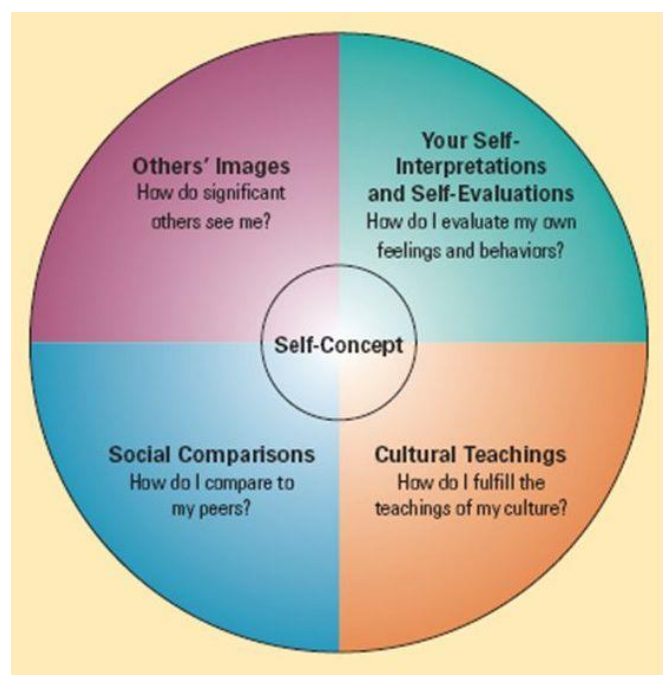

Sumber: Devito (2008)

Masyarakat meyakini bahwa 'almost without thinking, what gestures, styles of dress and grooming, and ways of walking and talking are considered "normal" for men and women. If a male acts "masculine," if his posture, talk, friends, dating, and job conform to masculine norms, his gender identity as a man will be taken for granted. If a male acts "feminine," he may not be considered a "normal" man' (Seidman, Nancy, dan Meeks, 2006), yakni seluruh bahasa tubuh yang normal adalah ketika laki-laki memiliki karakter maskulin dan perempuan memiliki karakteristik feminin. Pengkategorian ini membentuk identitas gender.

Menurut Samovar (2007), identitas gender merupakan makna dan interpretasi seseorang akan 'kelelakian' dan 'kewanitaan'. Sehingga gender selalu dikaitkan dengan jenis kelamin. Padahal, menurut Lips (1988), gender bukan produk dari jenis kelamin yang mana secara anatomi, jenis kelamin menunjukkan laki-laki dan perempuan; sedangkan gender dikonstruksi secara sosial, budaya dan psikologis menjadi maskulin dan feminin. Gender adalah sebuah keadaan dimana individu lahir secara biologis sebagai laki-laki dan perempuan, kemudian memperoleh pengkategorian secara sosial sebagai laki-laki dan perempuan melalui atribut-atribut maskulinitas dan femininitas yang sering didukung oleh nilai-nilai atau sistem simbol masyarakat yang bersangkutan (Branston \& Stafford, 2010).

Identity menurut Butler (dalam Litosseliti \& Sunderland, 2002) adalah "what you are or what characteristics you have," artinya bahwa identitas adalah siapa dan seperti apa karakter diri yang dimilki. Butler (1990) menjelaskan jika gender tidak otomatis terkait dengan jenis kelamin maka ada asumsi bahwa gender tidak hanya terdiri dari maskulin dan feminin. Identitas gender tidak jelas dan stabil, masih bisa berubah-ubah, tidak bisa dikategorisasikan dan diberi label, karena identitas terdiri dari banyak komponen. Kendati demikian, gender tidak hanya terdiri dari feminim dan maskulin. Bem menciptakan sebuah alat mengukur gender dalam skala dua dimensi ${ }^{1}$ yang diberi nama The Bem Sex Role Inventory. Berdasarkan respon dari item-item pada alat ukur ini,

\footnotetext{
${ }^{1}$ Skala dua dimensi merujuk pada Androgini (dari "andro" y ang berarti laki-laki, dan "gyn" berarti perempuan) yang mendeskripsikan seseorang yang memiliki karakter maskulin atau feminine sesuai dengan situasi tertentu, di mana androgini merupakan bentuk dari fleksibilitas seseorang dalam mengahadapi berbagai keadaaan dalam hidupnya
} 
individu diklasifikasikan memiliki salah satu dari orientasi peran gender yakni maskulin $^{2}$, feminine ${ }^{3}$, androgini ${ }^{4}$, dan undifferentiated ${ }^{5}$. Butler (1990) menyatakan bahwa daripada menjadi atribut tetap, gender dilihat sebagai sesuatu yang fluid (cair) yang dapat bergerak dan berubah dalam konteks dan waktu yang berbeda.

Menurut Campbell dan Storo (1994), stereotip gender adalah bagaimana seorang pria dan wanita berperilaku yang semestinya, yang mana stereotip muncul dari latar budaya suatu tempat dan berkembang dalam proses interaksi yang menuntut adanya perbedaan perilaku di ranah pribadi maupun pribadi.

Berikut ekspektasi akan kompetensi menurut gender:

Tabel 1

\begin{tabular}{|c|c|c|}
\hline Maskulin & Netral & Feminin \\
\hline Perilaku instrumental & Bertindak sesuai fakta & Perilaku ekspresif \\
\hline Gaya pencapaian langsung & $\begin{array}{l}\text { Kebiasaan belajar yang } \\
\text { seimbang }\end{array}$ & Gaya pencapaian yang unik \\
\hline membentuk & Peka terhadap isu terkini & Terampil beraliansi \\
\hline Negosiasi/Kompetisi & Berpikir cepat & Penolong/Mediasi \\
\hline Proaktif & Kreatif & Reaktif \\
\hline $\begin{array}{l}\text { Analitis/mampu memecahkan } \\
\text { masalah \& pembuat keputusan }\end{array}$ & Keterampilan sosial & Pengetahuan untuk diri sendiri \\
\hline $\begin{array}{l}\text { Membuat dampak yang jelas } \\
\text { dalam interaksi }\end{array}$ & & Sensitifitas nonverbal \\
\hline
\end{tabular}

Sumber: Sargent (1981)

Peran dan Stereotip Gender dalam Keluarga

Keluarga merupakan institusi terkecil dari masyarakat dan merupakan tempat pertama untuk mengajarkan berbagai hal kepada seorang anak. Pola asuh dan pendidikan yang diberikan orang tua membentuk pola pikir dan tingkah laku seseorang dalam berinteraksi di dalam masyarakat. Menurut Marcia (1993), latar belakang keluarga, significant others, ekspektasi dari lingkungan sosial (termasuk keluarga besar, sekolah dan peer group), terpaan terhadap variasi-variasi identitas, dan juga bagaimana figurfigur dewasa memberikan fondasi yang kokoh mengenai identitas.

Orang tua menjadi sumber inspirasi dan informasi, figur tokoh identifikasi anak, sehingga sikap dan perilaku orang tua akan memberi pengaruh pembentukan sikap dan perilaku anak (Marcia, 1993). Setelah orang tua, keluarga besar dan lingkungan sosial juga akan memberikan kontribusi melalui ekspektasi-ekspektasi dari diri seseorang. Menurut Frieze (1978), peran budaya pada perkembangan peran gender, dimulai dengan peran yang mendikte pengkategorisasian dan penggeneralisasian dalam proses kognitif seorang anak. Selanjutnya melalui berbagai alternatif, model budaya juga menyediakan

\footnotetext{
${ }^{2}$, individu yang feminin adalah seseorang memiliki angka yang tinggi pada sifat feminin dan memiliki angka rendah dari sifat maskulin

${ }^{3}$ individu yang maskulin adalah seseorang y ang memiliki angka yang tinggi pada sifat maskulin dan memiliki angka y ang rendah pada sifat feminin

${ }^{4}$ Individu androgini adalah laki-laki atau perempuan yang memiliki angka tinggi pada sifat maskulin dan feminin

${ }^{5}$ Individu undifferentiated memiliki angka yang rendah pada sifat maskulin dan femininnya
} 
suatu daya dorong dalam perubahan skemata kognitif seseorang. Peran budaya ini dimulai dari keluarga, dimana anak mengamati adanya perbedaan perilaku pada keluarga ke dalam sistem kategorinya. Pada skala yang lebih besar, struktur dan organisasi sosial, misalnya struktur keluarga dalam suatu masyarakat merupakan sumber data dimana seorang anak mempergunakannya untuk membentuk stereotip peran gender.

Stets \& Burke (2000) menyebutkan bahwa gender roles adalah segala harapan tentang perilaku yang diberikan terhadap satu gender; wanita dan pria. Masyarakatlah yang membentuk keyakinan bahwa seorang pria dan wanita memiliki kewajiban untuk memelihara perilakunya sesuai dengan peran yang seharusnya mereka lakoni dikehidupan bermasyarakat. Littlejohn \& Foss (2009) mengatakan bahwa teori ini digunakan untuk mengidentifikasi seseorang dalam kehidupan bermasyarakat sebagai seorang perempuan dan pria dengan peran yang dijalaninya berdasarkan struktur sosial yang ada. Weatherall (2002) menambahkan bahwa teori inilah yang menerangkan peran apa saja yang harus seorang wanita maupun pria lakukan diberbagai lapisan masyarakat. Weatherall (2002) mengatakan bahwa gender roles adalah bahasa yang menganalogikan batasan peran yang harus dilakoni oleh setiap gender; perempuan dan laki-laki.

Stereotip berasal dari gabungan dua kata Yunani, yaitu stereos yag berarti padat-kaku dan typos yang bermakna model. Stereotip diartikan sebagai representasi kognitif suatu kelompok yang mempengaruhi pandangan terhadap individu atas dasar keanggotaan kelompok tersebut (Gudykunst dan Kim, 1997). Stereotip adalah sebuah hasil dari proses adanya prasangka. Ktaz \& Barly (1933), menyatakan bahwa prasangka (prejudice) dan pelabelan (stereotype) tidak dapat dipisahkan keterkaitannya. Prasangka merupakan persepsi orang tentang seseorang atau kelompok lain. Prasangka (prejudice) merupakan persepsi (dalam tataran kognitif), sedang stereotip lebih kepada arti pelabelan kepada seseorang atau kelompok lain tersebut, termasuk sikap dan perilakunya terhadap mereka (sudah dalam tataran afektif, dan psikomotorik). Suatu stereotip, menurut Barker (2011) mereduksi seseorang menjadi sekumpulan ciri, sifat yang dibesar-besarkan dan biasanya negatif. Stereotip mereduksi, mengalamiahkan, dan menetapkan 'perbedaan' melalui bekerjanya kekuasaan, suatu stereotip menjadi penanda batas-batas antara apa yang 'normal' dengan golongan 'yang dihina', antara 'kita' dan 'mereka'.

Wood (1994) menambahkan bahwa setidaknya terdapat beberapa stereotip yang berkembang di sekitar masyarakat tentang pria dan wanita di tengah kemajuan era media, yakni:

1. Pria direpresentasikan sebagai sosok yang memiliki rasa kepercayaan diri yang tinggi, memiliki kompetensi dan kekuatan, juga memiliki posisi yang tinggi dengan statusnya.

2. Pria ditampilkan sebagai manusia yang memiliki karakter kuat, mandiri, agresif secara seksual, tidak mempunyai rasa takut, memiliki kemmapuan untuk mengontrol emosinya, dan tidak mungkin memiliki dan mengerjakan hal-hal yang bersifat feminin.

3. Pria diidentikkan sebagai individu yang tidak memiliki kemampuan untuk melakukan hal-hal yang dapat dilakukan oleh seorang perempuan, seperti mengasuh anak, memasak, dan pekerjaan wanita lainnya. 
4. Perempuan sebagai sosok ciptaan Tuhan yang memiliki kecantikan secara fisik dan hati dengan kelembutan dan kasih sayang yang dimilikinya sebagai seseorang yang dapat menjadi penghangat bagi keluarga dan sesama.

5. Perempuan minor yang dipersepsikan sebagai objek fantasi pria dalam memuaskan hasratnya. Disamping itu label yang buruk dilekatkan pula pada perempuan dalam kategori ini yakni sebagai ibu tiri yang jahat, penjaja seks, penjilat, dan sosok yang dikambinghitamkan sebagai tokoh utama dalam kisruh rumah tangga dan kedudukan pria dalam suatu pekerjaan.

Teori Interaksionisme Simbolik

Teori interaksionisme simbolik berada dalam lingkup tradisi sosiokultural (Cangara, 2011). Teori-teori yang berada dalam lingkup tradisi sosiokultural ini menjelaskan tentang apa yang dibangun dalam percakapan, bagaimana makna muncul dalam percakapan, dan bagaimana simbol-simbol diartikan melalui interaksi. Interaksionisme simbolik berfokus pada cara manusia membentuk makna dan susunan dalam masyarakat melalui percakapan. Littlejohn (2002) menjelaskan interaksionalisme simbolik merupakan perkembangan teori sosiologi yang menaruh perhatian pada komunikasi dan masyarakat, bahwa makna dan struktur sosial tercipta dan terpelihara dalam interaksi sosial.

Sedangkan menurut Charon (1979), interaksionisme simbolik adalah sebuah perspektif dalam psikologi sosial yang secara khusus berhubungan dengan sosiologi. Bukan hanya fokus pada individu dan karakteristik personalnya atau bagaimana struktur sosial atau situasi sosial membentuk perilaku individu, interaksionisme simbolik juga fokus pada interaksi alami, aktivitas sosial yang dinamis diantara individu tersebut.

Teori interaksi simbolik pada akhirnya memberikan sebuah teori aksi ( $a$ theory of action) yang bisa dipakai untuk memperoleh pemahaman (vestehen) tentang tindakan individu oleh pemahaman (vestehen) tentang tindakan individu, berikut asumsi dasar interaksi simbolik:

Gambar 2

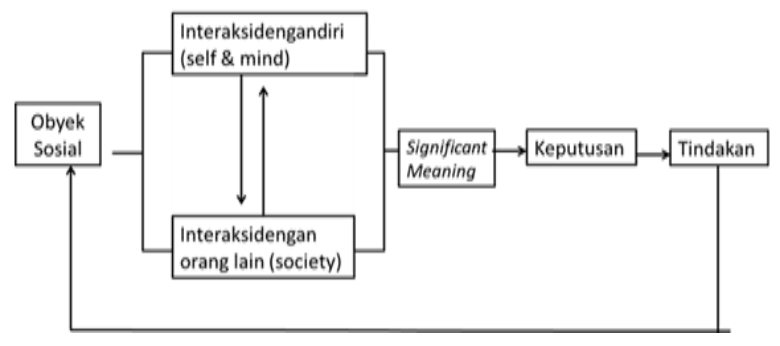

Model Aksi Charon (1998), disederhanakan.

Empat elemen penting menjadi bahan pertimbangan dalam proses self interaction adalah (a) tujuan, (b) perspektif, (c) situasi (konteks) dan (d) the past atau pengalaman masa lalu yang berkait dengan obyek sosial. Elemen lain yang juga ikut mempengaruhi definsi situasi adalah obyek-obyek sosial yang muncul yang secara langsung atau tidak langsung memiliki kaitan dengan obyek sosial pertama. Peneliti mendefinisikan 
interaksionisme simbolik sebagai sebuah teori komunikasi interpersonal yang menekankan tentang bagaimana makna, simbol, dan struktur sosial membentuk dan dibentuk oleh perilaku individu yang tercipta dan terpelihara secara dinamis dalam interaksi sosial

\section{METODOLOGI PENELITIAN}

Penelitian ini menggunakan metode penelitian kualitatif. Metode pengumpulan data untuk mendapatkan informasi adalah terlibat atau terjun langsung, mengadakan observasi, wawancara terbuka dan analisis dokumentasi. Pada observasi, peneliti terlibat dengan informan atau sumber data penelitian dalam kegiatan sehari-hari. Wawancara yang digunakan dalam penelitian ini adalah wawancara tak terstruktur yaitu menunjuk pada pemahaman suatu perilaku yang kompleks dari informan. Kemudian, dokumentasi dilakukan dengan cara mempelajari dan mencatat bahan-bahan bacaan, surat kabar, jurnal, makalah, dokumen dan laporan-laporan, serta bahan-bahan lain yang berkaitan dengan topik pokok atau fokus penelitian ini (Sugiono, 2005).

Sampel dalam penelitian kualitatif disebut dengan informan, yaitu orang-orang yang dipilih diwawancarai atau diobservasi sesuai tujuan penelitian (Kriyantono, 2009). Infroman pada penelitian ini berjumlah 3 (tiga) orang yakni dengan karakteristik 1) lakilaki, 2) mengetahui dan paham akan konsensus umum stereotip gender di dalam masyarakat, serta 3) pernah mengalami krisis identitas terkait gender. Adapun informan pada penelitian ini didapatkan melalui teknik snowball sampling. Teknik ini merupakan teknik penentuan sampel yang awalnya berjumlah kecil, kemudian berkembang semakin banyak. Orang yang dijadikan sampel pertama diminta memilih atau menunjuk orang lain untuk dijadikan sampel lagi, begitu seterusnya sampai jumlahnya lebih banyak (Kriyantono, 2009). Kemudian teknik analisis data yang digunakan adalah data collection, data reduction, data display, dan conclusion: drawing/verifying.

\section{HASIL DAN PEMBAHASAN}

Seorang anak laki-laki yang menunjukkan sifat feminin di dalam keluarga dengan stereotip maskulinitas di dalam masyarakat yang kuat membuat orang tua memikirkan berbagai cara agar si anak tidak memiliki karakteristik tersebut. Penelitian ini menemukan bahwa para informan memiliki pengalaman yang berbeda satu sama lain. Perbedaan yang dialami informan berasal dari pengalaman dan latar belakang keluarga terutama terkait dengan pola asuh keluarga dan interaksi di dalam lingkungan peer group.

Feminitas pada laki-laki dianggap sebagai sesuatu yang tidak bisa ditoleransi. Menjadi anak yang berbeda, dianggap kemayu atau 'bege' yang artinya bujang gadis. Pemahaman akan kemayu berarti menyukai sesama laki-laki dan seterusnya, yang mana hal tersebut merupakan identitas yang berbeda dan tidak berkaitan.

Informan pertama menyatakan bahwa mereka mengalami fase dimana dirinya menjadi anak yang benar-benar diarahkan menjadi pribadi yang maskulin, seorang anak laki-laki harus berani, tidak boleh manja, tidak boleh cengeng sehingga tidak ada pilihan menjadi lelaki kemayu. Di dalam lingkungan sosial, terutama dalam tatanan kebudayaan Minangkabau, laki-laki kemayu mendapatkan tempat yang tidak sama dengan masyarakat pada umumnya. Penolakan menjadi hal yang biasa apabila ada anggota 
masyarakat yang dianggap berbeda, bahkan ditanamkan kepada anak-anak sedari kecil sebagai bahan pelajaran agar mengikuti kodrat. Informan yang kedua, sedari kecil menyukai kegiatan di dalam rumah dan berkumpul dengan teman-teman perempuan,ia kemudian diminta untuk mengikuti kegiatan yang bersifat outdoor, dan dilakukan secara berkelompok, bersaa teman laki-laki. Sering kali ia menolak karena tidak mau berintraksi dengan sesama anak lelaki yang sarat dengan kekerasan.

Pemahaman akan laki-laki maskulin sedari kecil ditanamkan orang tua secara baik dengan ajakan langsung maupun tidak langsung. Karena dari awal masyarakat telah membagi gender menjadi maskulin dan feminine, kejanggalan muncul apabila jenis kelamin yang diidentifikasi melakukan tindakan di luar karakteristik tersebut. Sebagai contoh, bergaul dengan teman perempuan yang lebih banyak dari pada teman laki-laki; melakukan kegiatan indoor lebih sering dari kegiatan outdoor, mengenakan suatu jenis fesyen tertentu atau pakaian yang bukan ditujukan untuk kategori gender seperti mengenakan warna-warna tertentu. Sehingga informan merasa harus mencitrakan dirinya dengan satu identitas gender saja, yakni feminine atau maskulin.

Krisis yang terjadi di dalam diri informan terjadi karena ada perbedaan antara ketetapan yang tertulis maupun tidak tertulis di dalam masyarakat dengan apa yang dialami dan dipikirkan, serta dilakukan oleh informan. Menjelang adanya penerimaan oleh pihak keluarga dan lingkungan sekitarnya, para informan merasakan krisis identitas. Kesulitan dalam mengekspresikan diri menjadi tantangan bagi diri informan.

Namun, tantangan terbesar berada pada pengaburan atau penyatuan identitas yang satu dengan yang lainnya, seperti gender ke dalam seksualitas (Davis, 1992). Stereotip mengenai gender pun mau tidak mau diasosiakan menjadi sesuatu yang heteroseksual. Gender, menjadi sesuatu yang erat kaitannya dengan seksualitas. Seorang laki-laki haruslah bersifat seperti laki-laki, yang tentu saja tidak lepas dari sifat-sifat maskulin, dan begitu juga perempuan. Perbedaan yang ada, sekecil apa pun akan menjadi permasalahan, apalagi jika lingkungan tempat tinggal dan hidup seseorang merupakan lingkungan yang patuh menganut nilai-nilai suatu agama ataupun kebudayaan (Butler, 1990). Krisis menjadi menjadi bagian dari kehidupan mereka karena krisis merupakan proses dari setiap keputusan yang akhirnya membentuk diri mereka saat ini. Setiap informan mengalami krisis yang berbeda, terutama ketika melewati masa pubertas. Mengawali pemaparan krisis yang dialami setiap informan, seperti adanya pengalaman berinteraksi dengan lawan jenis, beberapa kali mengalami kegagalan berkomunikasi karena informan dianggap tidak seperti laki-laki kebanyakan yang maskulin di luar harapan perempuan tersebut.

Stereotip gender mempengaruhi bagaimana perilaku pria dan wanita dan seberapa baik aktivitas mereka dalam aktivitas tertentu. Individu menghadapi ancaman stereotip ketika mereka menyadari bahwa mereka dikenai penilaian berdasarkan gender oleh masyarakat. Mereka mungkin juga mengembangkan ancaman stereotip karena kekhawatiran akan stereotip negatif yang memuaskan diri sendiri tentang kelompok gender mereka. Peran gender dan stereotip mempengaruhi pria dan wanita dengan cara dan individu yang berbeda dapat dinilai dari seberapa baik mereka menyesuaikan diri dengan stereotip tradisional ini. 
Perlahan dalam interaksi sosial, informan menemukan bahwa seiring berjalannya waktu karakteristik tersebut berkembang. Manusia tidak bisa hanya dikotakkan berdasarkan satu stereotip gender, karena seluruh karakteristik seharusnya bisa dikembangkan dan diterapkan dalam interaksi sosial agar terjalin komunikasi efektif. Informan juga menyatakan bahwa masyarakat tidak bisa membatasi orang untuk menjadi seperti yang diinginkan oleh masyarakat hanya karena beberapa karakter dan perilaku yang tidak dapat diterima ketika berinteraksi dalam masyarakat. dan androgini merupakan salah satu bentuk ketidakpatuhan terhadap sistem sosial di dalam masyarakat yang dualisme karena androgini memungkinkan seseorang untuk menjadi pribadi yang memiliki kedua karakteristik tersebut.

Menurut Bem (1975), seseorang yang memiliki identitas gender yang sehat adalah mereka yang bisa menyeimbangkan karakteristik maskulin dan femininnya, tidak hanya terpaku pada karakter maskulin atau feminine saja. Lebih jauh lagi, Bem menyatakan dengan contoh bahwa seorang perempuan yang lembut, sensitif dan berbicara dengan nada yang pelan (karakteristik feminine tradisional), namun juga ambisius, mandiri, dan atletik (karakteristik maskulin tradisional); di sisi lain seorang laki-laki yang kompetitif, dominan dan berani mengambil resiko, terlihat memiliki karakteristik penyayang, simpatik, riang; di mana sesungguhnya keduanya menunjukkan keseimbangan gender. Kategori androgini sebagai gender yang seimbang tetap sulit diterima oleh masyarakat.

Seiring berjalannya waktu informan menyadari bahwa pemikiran orang tua dan peer group pada saat itu muncul karena dibentuk oleh terpapar berbagai ideologi kategorisasi gender tersebut agar diterima dalam sistem sosial. Perbedaan dianggap sebagai suatu yang menyimpang. Informan tetap mengembangkan karakter yang dianggap bisa membuatnya bertahan di dalam interaksi sosial tersebut. Di dalam interaksi sosial informan pada umumnya memiliki relasi yang baik dengan lingkungan sekitar serta dalam melakukan manajemen emosi. Semakin banyak interaksi yang dilakukan para informan menunjukkan semakin banyak ragam masyarakat di luar tempat tinggalnya yang memiliki keberagam identitas, dan yang akhirnya dia miliki sampai saat ini, menjadi laki-laki yang lebih lembut dan kemayu bukan merupakan hal yang salah. Informan juga memberikan pemahaman bahwa dirinya memang berbeda dari masyarakat pada umumnya, dan tidak menjadikan itu sebagai sebuah kekurangan melainkan keunggulan. Dan perbedaan itu mulai diterima dimulai dari orang tua serta orang-orang di lingkungan sekitarnya.

\section{PENUTUP}

Dalam berkomunikasi, seseorang dituntut harus memahami lingkungan tempat mereka melakukan aktivitas komunikasi. Semua muncul disebabkan adanya interaksi antara satu sama lain, yakni individu dengan indvidu, serta individu di dalam masyarakat. Dalam melakukan interaksi dibutuhkan kemampuan untuk saling menghormati dan menghargai akan identitas, pengalaman, juga keberadaan wanita dan pria. Wanita dan pria memang diciptakan berbeda secara biologis, namun memiliki kesempatan yang sama untuk melakukan apa pun dan menjadi siapa pun. Konsep diri serta identitas yang didukung komunikasi efektif dalam keluarga akan menjadi modal bagi individu untuk dapat bertahan di dalam interaksi sosial kehidupan bermasyarakat. Untuk itu dibutuhkan kemampuan untuk mempelajari dan memahami karakteristik baik feminin maupun 
maskulin. Identitas androgini dibutuhkan dalam diri seseorang agar mampu beradaptasi secara fleksibel tergantung situasi.

\section{DAFTAR PUSTAKA}

Barker, Chris. (2011). Cultural Studies: Theory and Practice, terj. Nurhadi, Cultural Studies: Teori \& Praktik, Edisi ke-7. Bantul: Kreasi Wacana.

Bem, Sandra Lipzits. (1975). Sex Role Adaptability: One Consequence of Psychological Androgyny dalam Journal of Personality and Social Psychology 1975, Vol. 31, No. 4, 34643. Stanford University.

Branston, Gill \& Roy Stafford. (2010).The Media Student's Book. $5^{\text {th }}$ Ed. New York: Routledge.

Butler, Judith. (1990). Gender Trouble: Feminism and the Subversion of Identity. New York: Routledge.

Campbell, P. B., \& Storo, J. N. (1994). Girls Are... Boys Are... : Myths, Stereotypes \& gender Differences. Office of Educational Research and Improvement

Cangara, Hafied. (2011). Pengantar Ilmu Komunikasi. Jakarta: PT Raja Grafindo.

Charon, Joel M. (1979). Symbolic interactionism: An introduction, an interpretation, an integration. Prentice Hall PTR

Davis, Fred. (1992). Fashion, Culture, and Identity. Chicago: University of Chicago Press.

Devito, J. A. (2008). Human Communication: The Basic Course. Pearson College Division.

Epstein, S. (1973). The Self-Concept Revisited, Or a Theory of a Theory. American Psychologist , 28, 404-414.

Lips, H. M. (1988). Sex \& Gender An Introduction. California: Mayfield Publishing Company.

Littlejohn, S. W., \& Foss, K. A. (2009). Encyclopedia of Communication Theory. Thousand Oaks, California, USA: Sage Publications, Inc.

Griffin, EM. (2006). A First Look At Communication Theory $6^{\text {th }}$ edition. New York : McGraw Hill

Gudykunst, William B. \& Young Yun Kim. (1997). Communicating With Strangers: An Approach to Intercultural Communication, Ed. $3^{\text {rd }}$. Boston: McGraw-Hill.

Kriyantono, Rachmat. (2008). Teknik Praktis Riset Komunikasi. Jakarta: Prenada Media Group

Katz, D., \& Barly, K. (1933). Racial stereotypes of one hundred college students. Journal of Abnormal and Social Psychology, 28, 280-290

Littlejohn, Stephen W. (2002). Theories of Human Communication 7th edition. California: Wadsworth

Littlejohn, S. W., \& Foss, K. A. (2009). Encyclopedia of Communication Theory. Thousand Oaks, California, USA: Sage Publications, Inc. 
Marcia, J.E., Waterman, A.S., Matteson, D.R., Archer, S.L., Orlofsky, J.L. (1993). Ego Identity: A Handbook for Psychosocial Research. New York: Springer-Verlag New York Inc.

Patton, M. Q. (2002). Qualitative Research and Evaluation Methods (3 ed.). Thousand Oaks, California, USA: Sage Publication Inc.

Myers. (1996). Social Psychology. The McGraw-Hill Companies, Inc.

Oskamp, S., \& Schultz, P. W. (2005). Attitudes and Opinions (3rd Edition ed.). New Jersey: Lawrence Erlbaum Associates, Inc.

Samovar, Larry A., Porter, Richard E., \& McDaniel, Edwin R. (2007). Communication Between Cultures $6^{\text {th }}$ edition. USA : Thomson Wadsworth.

Sargent, A. G. (1981). Training for Androgynous Behavior in Organizations. Journal of Experiential Learning and Simulation, 3, 37-46.

Seidman, S., Nancy, F., \& Meeks, C. (2006). Handbook of The New Sexuality Studies. London, UK: Routledge Taylor \& Francis Group.

Stets, J. E., \& Burke, P. J. (2000). Femininity/Masculinity. Department of Sociology.

Sugiono. (2005). Memahami Penelitian Kualitatif. Bandung: Alfabeta

Weatherall, A. (2002). Gender, Language, and Discourse. New York: Routledge.

Wood, J. T. (1994). Gendered Media: The Influence of Media on Views of Gender. Gendered Lives: Communication, Gender, and Culture , 231-244. 